\title{
ArcheoSciences
}

Revue d'archéométrie

33 (suppl.) | 2009

Mémoire du sol, espace des hommes

\section{Testing of multi-coil FDEM sensors on a field model with magnetic susceptibility contrast}

David Simpson, Marc Van Meirvenne, Erika Lück, Jörg Rühlmann and Jean Bourgeois

\section{(2) OpenEdition}

12 Journals

\section{Electronic version}

URL: https://journals.openedition.org/archeosciences/1832

DOI: 10.4000/archeosciences. 1832

ISBN: 978-2-7535-1599-4

ISSN: $2104-3728$

Publisher

Presses universitaires de Rennes

Printed version

Date of publication: 30 October 2009

Number of pages: $357-359$

ISBN: 978-2-7535-0943-6

ISSN: 1960-1360

\section{Electronic reference}

David Simpson, Marc Van Meirvenne, Erika Lück, Jörg Rühlmann and Jean Bourgeois, "Testing of multi-coil FDEM sensors on a field model with magnetic susceptibility contrast", ArcheoSciences [Online], 33 (suppl.) | 2009, Online since 30 October 2011, connection on 01 February 2022. URL: http://journals.openedition.org/archeosciences/1832 ; DOI: https://doi.org/10.4000/archeosciences. 1832 


\title{
Testing of multi-coil FDEM sensors on a field model with magnetic susceptibility contrast
}

\author{
David Simpson*, Marc Van Meirvenne*, Erika LüCK**, \\ Jörg RüHLMANN ${ }^{* * *}$ and Jean BourgeoIs ${ }^{* * * *}$
}

Key words: Electromagnetic induction sensor, Magnetic susceptibility, Coil orientation, Coil separation, Spatial sensitivity.

\section{INTRODUCTION}

The main advantage of frequency domain electromagnetic induction (FDEM) sensors is the simultaneous measurement of both electrical conductivity and magnetic susceptibility. Nevertheless, this sensor type is still not routinely used in geoarchaeological prospection (English Heritage, 2008). Although both the electrical conductivity and the magnetic susceptibility measurement has been related to electrical resistivity and magnetometer measurements respectively (Kvamme, 2006), these relationships are not always straightforward (Linford, 1998). The recent development of multiple coil instruments creates new opportunities for archaeological prospection (Simpson et al., 2009) but at the same time complicates the interpretation of the different signal responses. (Tabbagh, 1986) investigated the response of different coil orientations to layered-earth and three-dimensional objects with theoretical modeling for a $1.5 \mathrm{~m}$ coil separation. But an exhaustive study with different sensor configurations on field models was not conducted until now. Our aim is to present different FDEM sensor measurements over an object with magnetic susceptibility contrast constructed in a test site, to evaluate the effect of the coil configuration. A fluxgate gradiometer survey was also conducted for comparison.

\section{EXPERIMENTAL SETUP}

The test site was located in Großbeeren, close to Berlin (Germany). The soil consisted mainly of glacial till deposits of coarse sand with a minor fraction of poorly sorted stones. Therefore, the soil electrical conductivity was in general very low $\left(<10 \mathrm{mS} \mathrm{m}^{-1}\right)$. The magnetic susceptibility was fairly uniform over the test field, with higher values in the topsoil. Several objects were dug in to act as models for typical archaeological features, but here only one will be discussed. This object had a rectangular shape of $5 \mathrm{~m}$ in length, $0.5 \mathrm{~m}$ width and $0.5 \mathrm{~m}$ depth; it represented wall remains below the plough layer. A trench was dug of $0.8 \mathrm{~m}$ depth (Fig. 1) and filled with basalt powder up to $0.3 \mathrm{~m}$ depth, after which the remaining $0.3 \mathrm{~m}$ was filled up with the original topsoil. The volumetric magnetic susceptibility $(\chi)$ of the soil profile and the basalt was measured with a handheld instrument (kappameter KT-6, SatisGeo). The basalt had a $\chi$ of 0.01 (SI), which was significantly higher than the soil $\chi$ (smaller than $0.001 \mathrm{SI}$ ).

${ }^{*}$ Department of Soil Management, Ghent University, Coupure 653, B-9000 Gent, Belgium.

** Institute of Geosciences, University of Potsdam, Karl-Liebknecht-Str. 24, 14476 Golm, Germany.

*** Department of Plant Nutrition, Institute of Vegetable and Ornamental Crops Großbeeren/Erfurt, Theodor-Echtermeyer-Weg 1, 14979 Großbeeren, Germany.

**** Department of Archaeology and Ancient History of Europe, Ghent University, Blandijnberg 2, B-9000 Gent, Belgium. 
Two FDEM sensors were applied to test different coil configurations with a fixed transmitter frequency; the EM38MK2 (Geonics Limited) and the DUALEM-21S (Dualem inc.). The former instrument has two coil separations of 0.5 and $1 \mathrm{~m}$ in horizontal coplanar (HCP) orientation or in vertical coplanar (VCP) orientation, if rotated 90 degrees. The latter sensor can measure two coil separations (1(.1) and $2(.1) \mathrm{m}$ ) in two coil orientations, HCP and perpendicular (PERP), or when rotated 90 degrees in VCP orientation (and NULL orientation). Both sensors record the in-phase as well as the quadrature-phase response (proportional to $\chi_{a}$ and $\sigma_{a}$ respectively). The sensors were operated at $0.2 \mathrm{~m}$ height on a hand-pushed cart with a dGPS, parallel to the survey lines and perpendicular to the length of the trench. The in-line distance was maximally $0.1 \mathrm{~m}$ and the cross-line distance $0.5 \mathrm{~m}$.

The magnetic gradiometer measurements were conducted with a Fluxgate FM18 (Geoscan Research) at $0.25 \mathrm{~m}$ in-line and $0.5 \mathrm{~m}$ cross-line distance on a fixed grid.

\section{ResUlts}

The background value of the magnetic measurement was subtracted to be able to compare the magnitude of the object's response (Fig. 2). Three criteria were used to evaluate the different sensor responses: absolute magnitude, compactness and changing direction (resulting in positive and negative values). The responses to the magnetic object differed a great deal between the different sensor configurations. The $1.1 \mathrm{~m}$ PERP (Fig. 2a) and $2 \mathrm{~m} \mathrm{HCP} \mathrm{(Fig.} \mathrm{2d)} \mathrm{showed} \mathrm{the}$ strongest response and a compact, unidirectional pattern (the $2 \mathrm{~m} \mathrm{HCP}$ had a slight negative dip outside the strong, positive response). The $1 \mathrm{~m} \mathrm{VCP}$ configuration was not as strong, but was unidirectional and compact. Other configurations either suffered from low signal magnitude (Figs 2c, g and h), a wide anomaly (Figs. 2b and f) or a bidirectional response pattern (Figs 2b, c and f). The gradiometer anomaly was as expected very strong and with the typical bidirectional response. Based on these results, we concluded that the coil configuration of a FDEM sensor has a very large impact on the detection of small, magnetic contrasts.

\section{Acknowledgements}

The authors wish to thank Ute Spangenberg and Marko Dubnitzki for their support. This experiment was funded by a research project (G.0078.06) and a travel grant from the Research Foundation-Flanders (FWO).

\section{References}

English Heritage, 2008. Geophysical survey in archaeological field evaluation. English Heritage Publishing, Swyndon.

Linford, N. T., 1998. Geophysical survey at Boden Vean, Cornwall, including an assessment of the microgravity technique for the location of suspected archaeological void features. Archaeometry, 40: 187-216.

Kvamme, K. L., 2006. Integrating multidimensional geophysical data. Archaeological Prospection, 13: 57-72.

Simpson, D., Van Meirvenne, M., Saey, T., Vermeersch, H., Bourgeois, J., Lehouck, A., Cockx, L. and Vitharana, W. A. U., 2009. Evaluating the multiple coil configurations of the EM38DD and DUALEM-21S sensors to detect archaeological anomalies. Archaeological Prospection, 16: 1-13.

TabBagh, A., 1986. What is the best coil orientation in the Slingram electromagnetic prospecting method? Archaeometry, 28: 185-196.
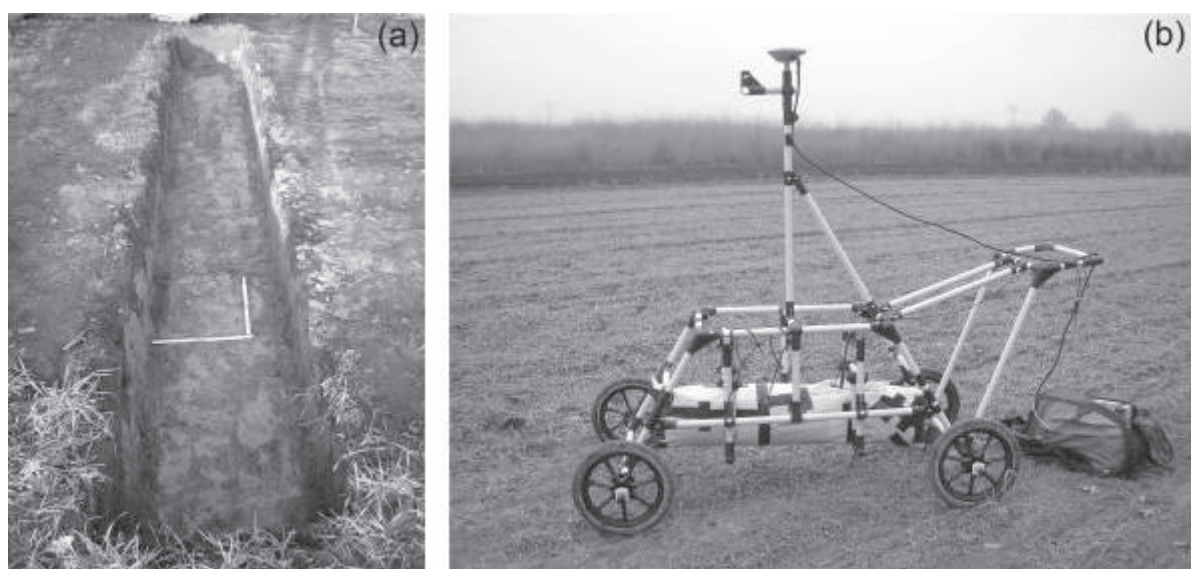

Figure 1: (a) Trench before filling up with basalt and topsoil. The length of the ruler is $0.4 \mathrm{~m}$. (b) Non-metallic cart (made in the Institute of Geosciences, University of Potsdam) with the EM38-MK2 wrapped in plastic, a GPS-antenna above and a GPS and field computer in a backpack.

ArCheoSCIEnCES, revue d'archéométrie, suppl. 33, 2009, p. 357-359 
Figure 2: In-phase response of (a) $1.1 \mathrm{~m}$ PERP, (b) $2.1 \mathrm{~m}$ PERP, (c) $1 \mathrm{~m} \mathrm{HCP}$, (d) $2 \mathrm{~m}$ HCP, (e) $1 \mathrm{~m}$ VCP ,(f) $2 \mathrm{~m}$ VCP, (g) $0.5 \mathrm{~m}$ HCP, (h) $0.5 \mathrm{~m}$ VCP. (i) Fluxgate gradiometer.
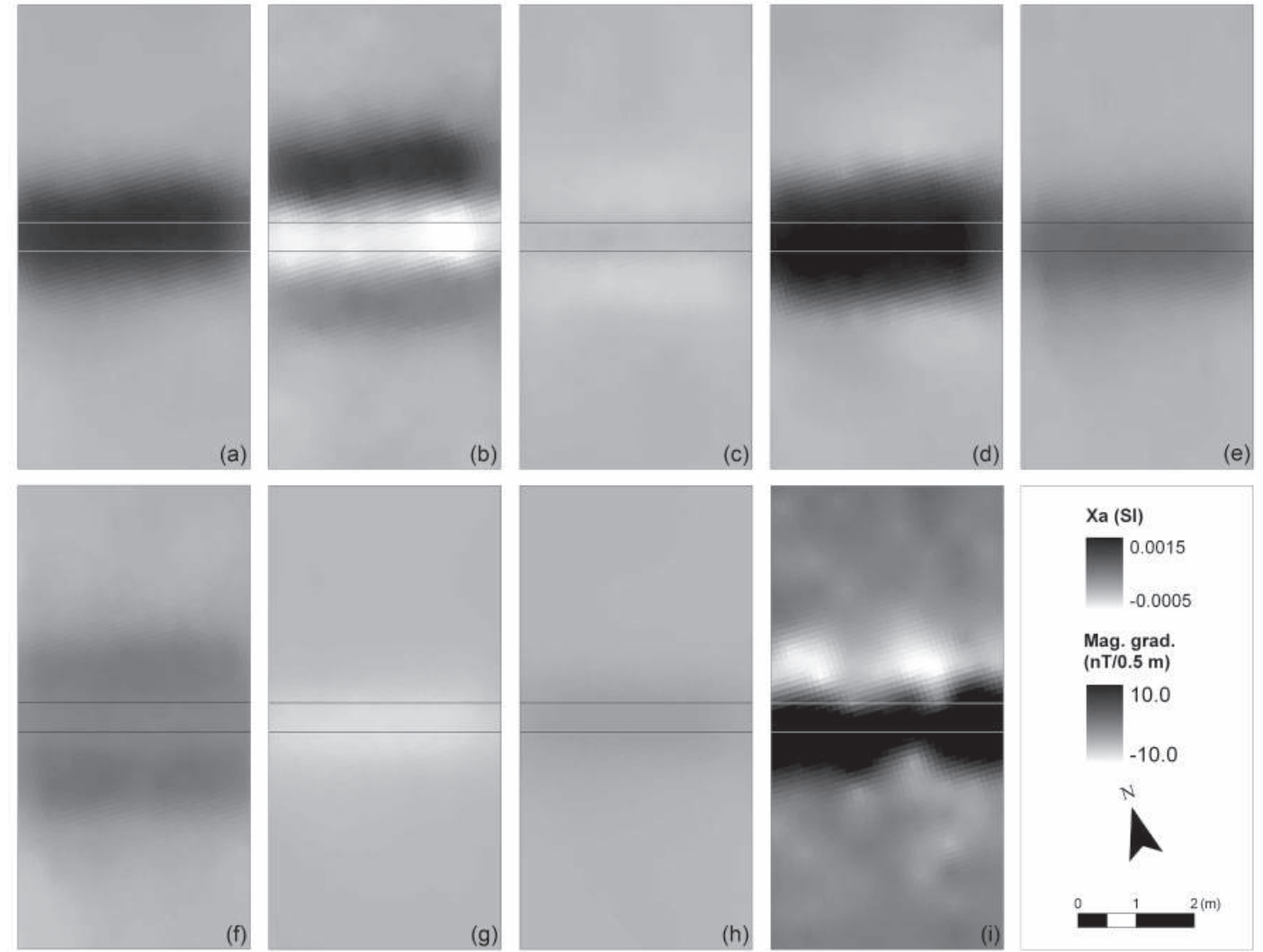

(e)

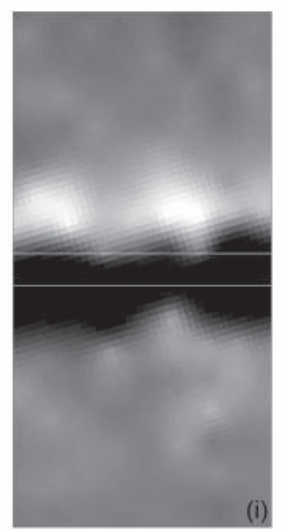

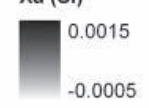

Mag. grad. (nT/0.5 m)

10.0

$-10.0$

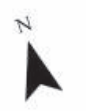

